\title{
Metallophospha-alkenes: A Simple Access and some Reactivities involving the Phosphorus Atom
}

\author{
Dietrich Gudat,a Edgar Niecke, ${ }^{*}$ Wolfgang Malisch,b Ullrich Hofmockel,b Sapé Quashie,c Alan H. Cowley, ${ }^{c}$ \\ Atta M. Arif, c Bernt Krebs, d and Mechthild Dartmannd \\ a Fakultät für Chemie der Universität, Postfach 8640, D-4800 Bielefeld, Federal Republic of Germany \\ b Anorganisch-chemisches Institut der Universität, Am Hubland, D-8700 Würzburg, Federal Republic of Germany \\ c Department of Chemistry, University of Texas at Austin, Austin, Texas 78712, U.S.A. \\ ¿Anorganisch-chemisches Institut der Universität, Corrensstrasse 36, D-4400 Münster, Federal Republic of Germany
}

The synthesis and studies on the reactive behaviour of metallophospha-alkenes are reported.

Phospha-alkenes are potential candidates for ambident reactivity, because they possess two energetically high lying, closely spaced molecular orbitals, $\Pi$ and $n(P) .{ }^{1}$ A change in reactivity, from 'olefinic' towards 'carbenic' character, has been verified recently for iminophosphanes, ${ }^{2}$ On this basis metallophospha-alkenes are of considerable interest, owing to the electron $\sigma$-donating effect of the transition metal ligand<smiles>ClP=C([AsH3])[AsH3]</smiles>

(1)
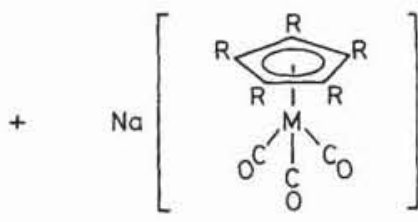

$(2 a-c)$

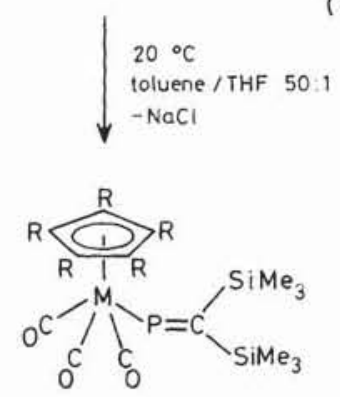

(3)

a; $\mathrm{M}=\mathrm{Mo}, \mathrm{R}=\mathrm{H}$

b; $M=M o, R=M e$

c; $M=W, R=H$

Scheme 1. (3a) m.p. $72-74{ }^{\circ} \mathrm{C}$ (decomp.), yield $56 \%$; (3b) m.p. $74-76{ }^{\circ} \mathrm{C}$ (decomp.), yield $76 \%$; (3c) m.p. 99-101 ${ }^{\circ} \mathrm{C}$ (decomp.), yield $63 \%$. which may destabilize the $\mathrm{n}(\mathrm{P})$ orbital and bring the 'carbene' character of the phospha-alkene to the fore.

Here we report the synthesis and studies on the reactivity of metallophospha-alkenes. ${ }^{3}$ The synthesis has been performed according to the procedure of heterogeneous metallation; ${ }^{4}$ a simple, versatile access to metallophospha-alkenes.

Treatment of chloro-bis(trimethylsilyl)methylenephosphane $^{5}(\mathbf{1})$ with sodium carbonylmetallates $(2 \mathrm{a}-\mathrm{c})$ yields the molybdenum and tungsten substituted phospha-alkenes (3ac) (Scheme 1), which are purified by filtration of the reaction mixture, evaporation of the solvent, and recrystallisation of the residue from hexane. Composition and constitution of $(3 \mathrm{a}-\mathrm{c})$ are proved by satisfactory elemental analysis, spectroscopic data, $\dagger$ and $X$-ray structure analysis $\ddagger$ in the case of (3a,c).

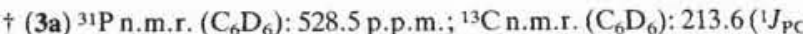
$109.5 \mathrm{~Hz}, \mathrm{P}=\mathrm{C})$; i.r. (hexane solution): $1996,1930,1915 \mathrm{~cm}^{-1}\left(v_{\mathrm{CO}}\right)$, $1065 \mathrm{~cm}^{-1}\left(v_{\mathrm{P}=\mathrm{C}}\right)$. (3b) ${ }^{31}$ P n.m.r.: 588.8 p.p.m.; ${ }^{13} \mathrm{C}$ n.m.r.: 218.0 $\left(J_{\mathrm{PC}} 106.9 \mathrm{~Hz}, \mathrm{P}=\mathrm{C}\right)$; i.r.: $1992,1924,1914 \mathrm{~cm}^{-1}\left(v_{\mathrm{CO}}\right), 1062 \mathrm{~cm}^{-1}$ $\left(v_{\mathrm{p}=\mathrm{C}}\right)$. (3c) ${ }^{31 \mathrm{P}}$ n.m.r.: 505.2 p.p.m. $\left({ }^{1} \mathrm{~J}_{\mathrm{wP}} 5 \mathrm{~Hz}\right) ;{ }^{13} \mathrm{C}$ n.m.r.: 209.8 $\left({ }_{\mathrm{PC}} 106.4 \mathrm{~Hz}, \mathrm{P}=\mathrm{C}\right)$; i.r.: $1992,1922,1910 \mathrm{~cm}^{-1}\left(v_{\mathrm{CO}}\right), 1068 \mathrm{~cm}^{-1}$ $\left(v_{p \rightarrow C}\right)$.

$\ddagger$ Crystal Data: $\mathrm{C}_{15} \mathrm{H}_{23} \mathrm{O}_{3} \mathrm{PSi}_{2} \mathrm{Mo}(3 \mathrm{a})\left[\mathrm{C}_{15} \mathrm{H}_{23} \mathrm{O}_{3} \mathrm{PSi}_{2} \mathrm{~W}(3 \mathrm{c})\right], M=$ 434.4 [522.3], monoclinic, space group $P 2_{1} / n, a=8.755(4)$ $[11.640(1)], b=18.607(4)[13.199(2)], c=12.351(5)[13.162(2)] \AA, \beta$ $=104.89(3)[91.63(1)]^{\circ}, U=1944[2021] \AA^{3}, Z=4, \lambda\left(\right.$ Mo $\left.^{3} K_{\alpha}\right)=$ $0.71069 \AA, \mu\left(\right.$ Mo- $\left.K_{\alpha}\right)=8.7[60.4] \mathrm{cm}^{-1}, D_{\mathrm{c}}=1.48[1.72] \mathrm{g} \mathrm{cm}^{-3}$. The structures were solved by direct methods and refined by full-matrix least-squares refinement to a current $R_{\mathrm{w}}=0.029[0.069]$, based on 3388 [2282] reflections with $F_{\mathrm{o}}>2[3] \sigma\left(F_{\mathrm{o}}\right)$. The atomic co-ordinates for this work are available on request from the Director of the Cambridge Crystallographic Data Centre, University Chemical Laboratory, Lensfield Road, Cambridge CB2 1EW. Any request should be accompanied by the full literature citation for this communication. 


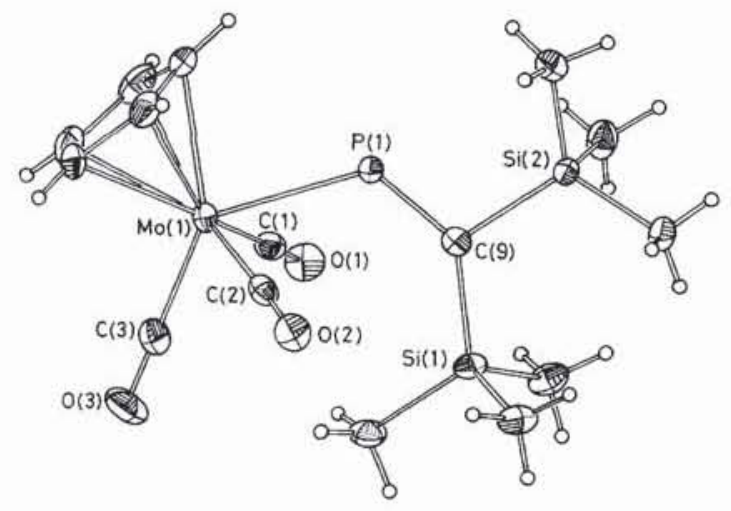

Figure 1. ORTEP view of the structure of (3a). Important bond lengths $(\AA)$ and angles $\left({ }^{\circ}\right)$ are [the corresponding values for $(3 \mathrm{c})$ are given in parentheses]: $\mathrm{P}(1)-\mathrm{C}(9) 1.665(3)$ [1.66(2)], $\mathrm{Mo}(1)[\mathrm{W}(1)]-$ $\mathrm{P}(1) 2.568(1)[2.569(5)], \mathrm{Mo}(1)[\mathrm{W}(1)]-\mathrm{C}(1) 1.980(3)[2.03(2)]$, $\operatorname{Mo}(1)[\mathrm{W}(1)]-\mathrm{C}(2) 1.967(3)[2.02(2)], \mathrm{Mo}(1)[\mathrm{W}(1)]-\mathrm{C}(3) 1.973(3)$ [2.03(2)]; $\mathrm{Mo}(1)[\mathrm{W}(1)]-\mathrm{P}(1)-\mathrm{C}(9) 123.45(11)[125.0(6)], \mathrm{P}(1)-\mathrm{C}(9)-$ $\mathrm{Si}(1) 135.8(2)[135.0(10)], \mathrm{P}(1)-\mathrm{C}(9)-\mathrm{Si}(2)$ 107.4(2) [108.3(9)].

The transition metal ligand causes a significant opening of the M-P-C angle [123 for (3a), $125^{\circ}$ for (3c)] (Figure 1), as compared to metal free phospha-alkenes. ${ }^{6}$ The $\mathrm{P}-\mathrm{C}$ bond lengths [1.67 for (3a), $1.66 \AA$ for (3c)] are in accord with the reported values for phospha-alkenes. ${ }^{6}$ The molecules are planar with respect to the MPCSi ${ }_{2}$-fragment and reveal the characteristic E/Z asymmetry of the $\mathrm{P}-\mathrm{C}-\mathrm{Si}$ angles. ${ }^{6} \mathrm{Destabi}-$ lization of the $n(P)$ orbital (as a consequence of the strong electron donating effect of the transition metal ligand) is evidenced by the large bathochromic shift of the $n-\Pi^{*}$ optical transition of the $\mathrm{P}=\mathrm{C}$ chromophore and the strong deshielding of the ${ }^{31} \mathrm{P}$ nucleus in the n.m.r. spectrum.

The transition metal increases the nucleophilicity of the $\lambda^{2}$-phosphorus atom and enhances its reactivity towards electrophilic reagents, which is in accord with the behaviour of $\lambda^{3}$-metallophosphanes. ${ }^{3}$ Reaction of (3c) with trifluoromethanesulphonic acid yields the complex (4), which exhibits the as yet unknown phospha-alkene, $\mathrm{HP}=\mathrm{C}\left(\mathrm{SiMe}_{3}\right)_{2}$, as a ligand. The $\mathrm{P}-\mathrm{H}$ bond is verified by the ${ }^{31} \mathrm{P}$ and ${ }^{1} \mathrm{H}$ n.m.r. data $\left(\delta^{31} \mathrm{P}\right.$ 187 p.p.m., $\delta^{1} \mathrm{H} 8.91, J_{\mathrm{HP}} 397 \mathrm{~Hz}$ ). The formation of (4) as the product in the reaction of a phospha-alkene with acid is of special interest: (3c) confirms the first example in which the regioselectivity (usually observed in the addition of protic substrates to $\mathrm{P}-\mathrm{C}$ double bonds) is reversed. In the same way, reaction of (3c) with trifluoromethanesulphonic acid methyl ester produces (5), via $P$-alkylation.

Treatment of (3c) with an equivalent amount of sulphur in benzene solution yields the tungsten substituted thiophosphaalkene (6). Its constitution is established by the downfield shift of the ${ }^{31} \mathrm{P}$ resonance signal ( $\delta 418$ p.p.m.) and the low value of the ${ }^{31} \mathrm{P}-183 \mathrm{~W}$ coupling constant $(J 14 \mathrm{~Hz})$. Presumably $(6)$ is produced by rearrangement of intermediate (7), corresponding to the formation of metallothioxophosphoranes from metallophosphanes under the same conditions. ${ }^{3}$

On heating $(3 \mathbf{a}-\mathbf{c})$, intramolecular substitution of one carbonyl ligand occurs with formation of the metallophosphaallenes $(8 \mathbf{a}-\mathbf{c})$. Compound $(\mathbf{8 c})$ has been described previously as the product in the reaction of $\mathrm{K}\left[\mathrm{Mo}(\mathrm{CO})_{3}\left(\mathrm{C}_{5} \mathrm{H}_{5}\right)\right]$ with (1) in tetrahydrofuran (THF). ${ }^{7}$ The conditions required for the extrusion of $\mathrm{CO}$ are strongly dependent on the transition metal: $(\mathbf{3 a}, \mathbf{b})$ are transformed in non-polar solvents

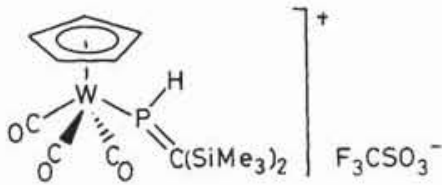

(4)

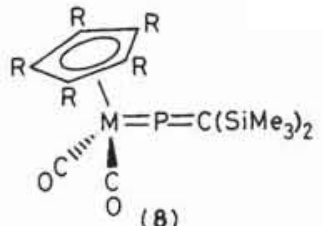

(8)
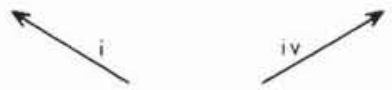

(3)
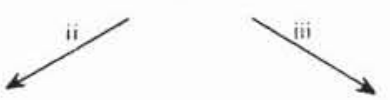

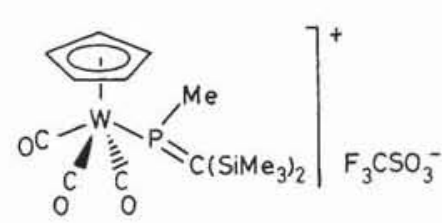

(5)

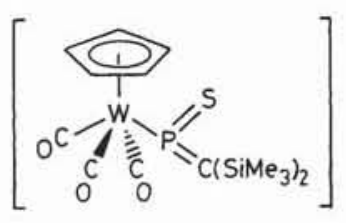

(7)

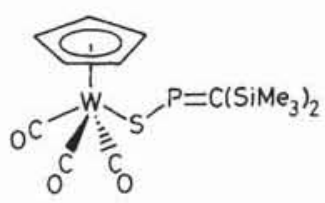

(6)

Scheme 2. i, $\mathrm{CF}_{3} \mathrm{SO}_{3} \mathrm{H}$ in $\mathrm{CH}_{2} \mathrm{Cl}_{2}$ at $-70^{\circ} \mathrm{C}$, then treatment with hexane and filtration; yield $45 \%$, m.p. $94-95{ }^{\circ} \mathrm{C}$ (decomp.), ${ }^{31} \mathrm{P}$ n.m.r. $\left(\mathrm{CH}_{2} \mathrm{Cl}_{2}\right)$ : 187 p.p.m. $\left(J_{\mathrm{pw}} 201, J_{\mathrm{PH}} 397 \mathrm{~Hz}\right)$; ${ }^{1} \mathrm{H}$ n.m.r. $\left(\mathrm{CD}_{2} \mathrm{Cl}_{2}\right): 8.91$ (P-H); i.r. (Nujol): $2058,1987,1960 \mathrm{~cm}^{-1}\left(v_{\mathrm{CO}}\right)$. ii, $\mathrm{CF}_{3} \mathrm{SO}_{3} \mathrm{Me}$ in toluene, $2 \mathrm{~h}$ at $30^{\circ} \mathrm{C}$, then filtration; yield $80 \%$, m.p. $89-90{ }^{\circ} \mathrm{C}$ (decomp.), ${ }^{31} \mathrm{P}$ n.m.r. $\left(\mathrm{CH}_{2} \mathrm{Cl}_{2}\right): 231$ p.p.m. $\left(J_{\mathrm{pw}} 198 \mathrm{~Hz}\right)$; ${ }^{1} \mathrm{H}$ n.m.r. $\left(\mathrm{CD}_{2} \mathrm{Cl}_{2}\right): 2.77\left(J_{\mathrm{PH}} 14.8 \mathrm{~Hz}, \mathrm{P}-\mathrm{CH}_{3}\right)$; i.r. (Nujol): 2054 , $1981,1940 \mathrm{~cm}^{-1}\left(v_{\mathrm{CO}}\right)$. iii, $\mathrm{S}_{8}$ in benzene, $2 \mathrm{~h}$ at $5^{\circ} \mathrm{C}$, then evaporating the solvent and washing the residue with hexane; yield $90 \%$, m.p. $51^{\circ} \mathrm{C}$ (decomp.); ${ }^{31 \mathrm{P}}$ n.m.r. $\left(\mathrm{C}_{6} \mathrm{D}_{6}\right): 417$ p.p.m. $\left(J_{\mathrm{Pw}} 14 \mathrm{~Hz}\right)$; i.r. (hexane solution): $2034,1960,1952 \mathrm{~cm}^{-1}\left(v_{\mathrm{CO}}\right)$. iv, (8a) $(\mathrm{M}=\mathrm{Mo}, \mathrm{R}$ $=\mathrm{H})$ and $(\mathbf{8 b})(\mathrm{M}=\mathrm{Mo}, \mathrm{R}=\mathrm{Me}): 45^{\circ} \mathrm{C}$ in benzene for $6 \mathrm{~h}$, then evaporating the solvent and recrystallizing from hexane. (8a): $51 \%$, m.p. $98-103{ }^{\circ} \mathrm{C}$ (decomp.), see ref. 7. (8b): $48 \%$, m.p. $67-69{ }^{\circ} \mathrm{C}$ (decomp.), ${ }^{31} \mathrm{P}$ n.m.r. $\left(\mathrm{C}_{6} \mathrm{D}_{6}\right): 493$ p.p.m.; i.r. (hexane solution): $1954,1891 \mathrm{~cm}^{-1}\left(v_{\mathrm{CO}}\right)$. (8c): reflux in $\mathrm{MeCN}$ for $6 \mathrm{~h}$, then evaporation of the solvent and recrystallizing from hexane; yield $43 \%$, m.p. $84-88^{\circ} \mathrm{C}$ (decomp.); ${ }^{31 P}$ n.m.r. $\left(\mathrm{C}_{6} \mathrm{D}_{6}\right): 446$ p.p.m. $\left(J_{\mathrm{PW}} 617 \mathrm{~Hz}\right)$; i.r. (hexane solution): $1952,1880 \mathrm{~cm}^{-1}\left(v_{\mathrm{CO}}\right)$.

and slightly above ambient temperatures completely into $(\mathbf{8 a}, \mathbf{b})$ while the formation of ( $3 \mathbf{c})$ requires several hours reflux in acetonitrile. The increase of p-character at the phosphorus atom in $(8 \mathrm{a}-\mathbf{c})$ is in agreement with $J_{\mathrm{PW}}, 5$ in $(3 \mathrm{c})$ and $617 \mathrm{~Hz}$ in $(\mathbf{8 c}) .^{8}$ The physical data as well as the studies on the reactivity indicate the 'carbene' character of these metallophospha-alkenes. 
J. CHEM. SOC., CHEM. COMMUN., 1985

We thank the Deutsche Forschungsgemeinschaft and the Fonds der Chemischen Industrie (E. N., W. M., B. K.) as well as the National Science Foundation and the Robert A. Welch Foundation (A. H. C.) for financial support.

Received, 12th August 1985; Com. 1202

\section{References}

1 W. W. Schoeller and E. Niecke, J. Chem. Soc., Chem. Commun., 1982, 569.

2 E. Niecke, D. Gudat, W. W. Schoeller, and P. Rademacher, J. Chem. Soc., Chem. Commun., 1985, 1050, and cited literature.
3 A. M. Arif, A. H. Cowley, and S. Quashie, J. Chem. Soc., Chem. Commun., 1985, 428; L. Weber, K. Reizig, R. Boese, and M. Polk, Angew. Chem., 1985, 97, 583.

4 W. Malisch, R. Maisch, I. J. Colquhoun, and W. MacFarlane, J. Organomet. Chem., 1981, 220, C1.

5 R. Appel and A. Westerhaus, Tetrahedron Lett., 1981, 22, 2159.

6 R. Appel, F. Kindl, and I. Ruppert, Angew. Chem., 1981, 93, 771; Angew. Chem., Int. Ed. Engl., 1981, 20, 731; A. H. Cowley, R. A Jones, J. G. Lasch, N. C. Norman, C. A. Stewart, A. L. Stuart, J. L. Atwood, W. E. Hunter, and H.-M. Zhang, J. Am. Chem. Soc., 1984, 106, 7015.

7 A. H. Cowley, N. C. Norman, and S. Quashie, J. Am. Chem. Soc., 1984, 106, 5007.

8 E. Gross, K. Jörg, K. Fiederling, A. Göttlein, W. Malisch, and R. Boese, Angew. Chem., 1984, 96, 705; Angew. Chem., Int. Ed. Engl., 1984, 23, 738. 